\title{
EXTENDING JUST WAR THEORY: THE JUS $A D$ BELLUM AND THE CAPABILITIES APPROACH TO ARMED CONFLICT
}

\author{
Deane-Peter Baker and Deborah Roberts \\ School of Philosophy and Ethics, University of KwaZulu-Natal
}

\begin{abstract}
As the nature of armed conflict continues to change, so the living ethical tradition that is just war theory has to adapt to meet new challenges. This paper offers a proposal for extending just war theory by incorporating into its framework a human capabilities-based ethic drawn from the work of Martha Nussbaum. This new approach is analysed in the light of two important recent challenges to just war theory: David Rodin's critique of the principle of national defence, and the emerging doctrine of humanitarian intervention. While the results of this analysis can only be considered to be preliminary, the authors argue that indications are that supplementing just war theory with Nussbaum's human capabilities-based ethic, or something similar, could yield significant benefits for the ethical analysis of contemporary armed conflicts.
\end{abstract}

\section{Introduction}

Plato is often credited with having said that "only the dead have seen the end of war". ${ }^{1}$ While the presence of war in human affairs has not abated, the nature of armed conflict has changed since the end of the Cold War. No longer can wars be thought of as being primarily fought between sovereign nations by uniformed members of those nations' military forces. The international order that for a long time defined the strictures within which armed conflict was understood and engaged with, and that was ushered in by the Peace of Westphalia in 1648, has in significant ways lost its grip on world affairs. No longer is it obvious that the Westphalian order of absolutely sovereign states is the best or even an adequate framework for understanding and evaluating contemporary warfare. In some respects this can be viewed as a positive development. As one commentator puts it:

Westphalia allowed international peace in Europe by allowing each state to control its own internal affairs. In practice, this meant that 
Catholic states would persecute Protestants, and Protestant states would persecute Catholics. International stability was to be bought, as we would say in modern parlance, at the price of human rights. ${ }^{2}$

just war theory, without question the dominant ethical paradigm for the ethical evaluation of armed conflict, came to prominence with the rise of the Westphalian state. The changing nature of contemporary armed conflict, as well as recent scholarship, has presented considerable new challenges to the just war framework. One important recent challenge to just war theory has come in the form of David Rodin's book War and Self-Defense, which argues that the traditional justification for national defence, which is generally held to rest on the individual's right to selfdefence, does not stand up to rigorous scrutiny. Other challenges have come from different quarters. One example is the increasing call for armed intervention in places where massive violations of human rights are taking place and where governments fall well short of their responsibility to protect and encourage the human development of those in their care, something about which traditional just war theory has had little to say. There are few people who believe that the genocide in Rwanda in 1994 was not a situation crying out for armed intervention by international forces. And much the same applies to the situation in the Sudan today. Indeed, George R. Lucas Jr. goes as far as to claim that "the prospective need for humanitarian interventions is rapidly becoming the principal justification for raising, equipping, training and deploying a ... military force." ${ }^{3}$ Another recently emerging challenge objects to the largely Western and Christian sources of just war theory, arguing that such a framework is not appropriate for application across our multicultural world. ${ }^{4}$

As is appropriate to a living ethical tradition like just war theory, there has recently been a range of proposed amendments and extensions to the theory aimed at addressing the challenges discussed above, as well as other recent challenges. Important recent examples include the emergence of two new categories of evaluation for the just war theory, the jus post bellum ${ }^{5}$ and the jus ad pacem. ${ }^{6}$ It is the purpose of this article to add to the debate over the contemporary form of just war theory by contending for the inclusion of a substantive notion of human flourishing, as articulated by the capabilities approach to human development, as part of the just war theory matrix of ethical analysis. It is our hypothesis that the capabilities approach to human development, particularly as articulated by Martha Nussbaum, displays genuine potential to underpin an ethic of just war that is capable not only of addressing war as we know it today, but also of comfortably coping with the increasingly common periods of 'neither peace nor war' that occur during the 
transition out of situations of warfighting. Because demonstrating the truth of this is a wide-ranging task beyond what can be achieved in one article, we shall concentrate on assessing the value of this approach by dealing with recent challenges to just war theory at the jus ad bellum level of analysis. In particular we focus on the cases of national defence and situations in which humanitarian intervention appears to be warranted. In a forthcoming article we will offer a preliminary analysis of the value of the capabilities approach for the analysis of the jus in bello.

As Nussbaum articulates it, the capabilities approach provides a basis for central constitutional principles that citizens have a right to demand from governments. ${ }^{7}$ This account of the normative justification of war, if successful, would then form part of a more comprehensive account of government responsibility. This would be advantageous on both a theoretical and a practical level. Theoretically, the importance of both national defence and humanitarian intervention (and, we suggest, everything in between) could be articulated in terms of a single framework of what has value in human life, in order for us to be able to make sense of just war in terms of and in relation to other things that have relevance for human flourishing. We would have one theory with which to articulate the normative ideals for both war and development, for example. Practically, since the problems that are faced in the developing world are all too often bound up with war and conflict, this single theory could provide the space for solutions that take account of the complex relations between conflict and development, rather than addressing only one half of the problem.

In selecting Martha Nussbaum's theory we do not intend to suggest that hers is the only, or even the best, approach to understanding the ethical imperative that the idea of human flourishing imposes upon us. We have selected Nussbaum's theory because it is already in wide use in the analysis of development ethics (which seems to us to be in important ways closely aligned to the ethics of armed conflict), and because it is one of the more fully developed theories of its kind currently on offer. Our goal here is only to illustrate the potential of incorporating something like Nussbaum's theory into the just war framework - indeed, one of the authors has argued elsewhere that a range of other theories, such as Charles Taylor's conception of the human, could play a very similar role. ${ }^{8}$ We hope that this article will open up serious debate over which theory is the most appropriate for the purposes outlined here. 
In the first section of this article, we set the scene by offering a brief overview of two important recent challenges to just war theory: David Rodin's argument against the ethical soundness of the principle of national defence, and the rise of the notion of humanitarian intervention. We then articulate the capabilities approach to human development, before outlining how such an approach might be applied to the realm of warfare.

Two things need emphasis at this point. First, it has to be emphasised that this article is merely sketching an outline: a skeleton of a potentially fruitful approach to the ethics of armed conflict. Again, a single article simply cannot adequately deal with the full range of questions regarding the feasibility of this approach that needs to be addressed, and it is our hope that this article will stimulate a debate that will bring to the fore challenges that we may not otherwise have considered.

Second, we are not claiming that Nussbaum herself advocates the applicability of the capabilities to cases of armed conflict. To the contrary, it is the key virtue of this article that it is the first to make a serious attempt to apply the capabilities approach to the ethics of warfare. The article is therefore a paradigm example of applied ethics.

\section{Recent challenges to traditional just war theory}

Although just war theory has long been the accepted basis for the ethical analysis of armed conflict, recent research and recent trends in the conduct of warfare have highlighted important new challenges to this ethical framework. In what follows we outline two of the more significant recent challenges to just war theory: David Rodin's critique of the principle of national defence and the emerging doctrine of humanitarian intervention.

\section{National defence $e^{9}$}

The right to national defence is taken, in just war theory, to be a right that is unconditionally possessed by all sovereign nation states. David Rodin, in his recent book War and Self-Defense argues that this just war principle of national defence is in fact morally indefensible.

Rodin points out that there are two main justifications of national defence, both of which rely on the established moral legitimacy of defence. The first approach involves a reductive argument in which national defence is seen as a collective form 
of individual defence, either in a literal sense, or as the claim that "the state has an obligation (and therefore a right) to defend its citizens in much the same way that a parent has the right to defend his or her child." ${ }^{10}$ Rodin argues, however, that neither of these versions of the reductive argument is successful. In the first case it is obvious that national defence is not simply "a lot of people exercising the right of self-defence at the same time and in an organised fashion". ${ }^{11}$ The other version of this argument also fails, because it is clear that the state "claims the right to defend itself, when none of its citizens is under imminent threat, and it can claim this right (under just war theory) even if it thereby puts its citizens under greater threat than if no defence were mounted." 12

The second main justification for national defence that is commonly put forward is what Rodin calls the 'analogical strategy'. Here the idea is that there is something about the state itself that grounds the right to national defence in a way that is analogous to the individual's right to defend him/herself. In answer to the question of what feature of the state could underpin such a right to national defence, Rodin points out that the most answers point to the common life of the community, defence of which is the responsibility of the state. Rodin addresses three interpretations of the common life as a potential end of national defence. ${ }^{13}$

The first, rooted in the Hobbesean social contract theory, gives the state the right to national defence on the grounds that the state provides order for its citizens. This is inadequate, Rodin argues, because what we need is "a moral reason not simply to defend order, but to defend a particular form of order; to defend our order". ${ }^{14}$ The second approach attempts to provide this reason with an argument from cultural relativism. The main problem here is that such a view fails to achieve the requisite level of objectivity for a universal right to national defence, for, in Rodin's view, the value of the common life in a particular community can only be understood by those within the community. This approach functions by claiming that this relativism means that we cannot legitimately judge across boundaries and therefore we should abstain from intervening in other communities. This, therefore (it is argued), gives rise to a right to national defence that is the flip side of this duty of non-interference. But this approach, Rodin argues, requires the acceptance of a relativism of value in all cases except for the case of non-intervention, which has to be objectively valuable in order for the argument to succeed. This, as Rodin recognises, is hopelessly ad hoc.

The failure of the relativist approach brings into view the final interpretation of a common-life-based right of national defence. In this approach what is needed is "a 
value that is both objective and particular - it must be objective and recognizable as valid across cultures, yet still provide a reason for defending a particular state or community". ${ }^{15}$ Freedom, autonomy, and particularly self-determination seem to some thinkers, most notably Michael Waltzer, to fit the bill here. These seem to be objectively valued goods that underpin all particular notions of the common good. Furthermore, the argument goes, these goods can only be protected if state sovereignty is respected, and so from this a universal right to national defence arises.

The obvious objection here, as Rodin rightly recognises, is that only democratic societies truly provide the opportunity for self-determination, and so this type of argument could only apply to democratic states. But this, of course, is insufficient to the task of finding a basis for the near-universal possession by states of the right to national defence, as this right is articulated in just war theory. Waltzer's attempts to rescue the self-determination account are tortured, argues Rodin, such that selfdetermination becomes distorted beyond recognition.

Rodin concludes that, since none of the available justifications work, the right to national defence, as articulated in just war theory, is morally indefensible.

\section{Humanitarian intervention}

In international law the right to national defence is held to rest on the principles of state sovereignty and non-intervention. In apparent conflict with these principles (which are generally seen as absolute rather than conditional), in recent years we have seen the rise of an emerging doctrine of 'humanitarian intervention', which we have seen put into practice in places like Kosovo and the Sudan. Rodin contends, however, that this emerging doctrine does not undermine the idea of state sovereignty, because such interventions are only justified in the most extreme situations, those involving "abuses of human rights which are so severe that they 'shock the conscience of mankind', typically involving genocide, mass expulsion, or starvation". 16

It is our contention, however, that the extremity of the situations generally held to justify humanitarian interventions is irrelevant to the question of the impact of this doctrine on the idea of state sovereignty. The fact that humanitarian interventions are only justified in particularly extreme situations seems to us to be simply a consequence of one aspect of the doctrine of proportionality - in this case the recognition that a military intervention will often result in greater hardship than the original offence that it aimed to rectify. Like self-defence, humanitarian intervention 
by means of military force is only one of a range of possible interventions that may be justified in proportion to the appropriateness of their deployment. And of course we $d o$ feel that nations are justified in intervening in all sorts of ways in the light of some deeply held views of the nature of human development - take for example the positive intervention of pouring funding for the education of women into a country where this is not something that has generally been valued.

The point is that international practice and moral sentiment, expressed through humanitarian interventions, increasingly views state sovereignty as conditional. A salient example is the recent report by the International Commission on Intervention and State Sovereignty, which deliberated on the issue of humanitarian intervention in the light of recent experiences in places such as Rwanda, Kosovo, Bosnia and Somalia, and concluded that the following basic principles ought to be applied:

- State sovereignty implies responsibility, and the primary responsibility for the protection of its people lies with the state itself.

- Where a population is suffering serious harm as a result of internal war, insurgency, repression or state failure, and the state in question is unwilling or unable to halt or avert it, the principle of non-intervention yields to the international responsibility to protect. $^{17}$

Statements such as these reflect clearly that the notion of humanitarian intervention is here to stay. What is needed, therefore, is for an approach to the ethics of armed conflict that can both account for the prima facie right of the state to defend itself from outside aggressors, while at the same time providing an ethical basis for humanitarian interventions.

While there have been attempts in recent years to propose amendments to existing just war theory in order to accommodate the doctrine of humanitarian intervention, these amendments are generally ad hoc. More often humanitarian intervention is viewed as a sort of exception to just war theory ${ }^{18}$, which, as David Rodin points out, in its contemporary guise takes the principle of national sovereignty to be so important that the only uncontentious use of armed force is in defence of that sovereignty. ${ }^{19}$ Terry Nardin points out that a close reading of the history of just war thinking reveals two competing strands of thought: one that (following the likes of John Stuart Mill) gives primacy to a principle of non-intervention, and one that views various forms of injustice as legitimising the resort to interventionist force..$^{20}$ 
The former approach has clearly come to dominate, and attempts to revive the latter tradition have met with little success. Mona Fixdal and Dan Smith, for example, try to argue that there is sufficient scope within contemporary just war theory to deal with humanitarian intervention. When it comes to the specifics, however, their position is only established by considerable fudging. For example, when Fixdal and Smith discuss the idea of legitimate authority they write:

There may be no ultimately satisfactory general answer to the question of legitimate authority. The just war tradition's inclination against binding principles leads us to expect different answers from case to case. For humanitarian intervention, the legitimate authority criterion can be regarded as responsive to the other criteria. The more glaring the injustice to be remedied, the less clear the authority may need to be; conversely, the more there are alternatives to the use of force, the more solidly grounded the authority for intervention must be. ${ }^{21}$

While there is certainly merit in some of the many responses to this and other challenges to just war theory that have emerged in recent years, we believe that there is room in the debate for at least one more approach. It is our contention, as we shall argue below, that the capabilities approach has the potential, being both sufficiently particular and sufficiently universal, to account both for the right to national defence and humanitarian intervention, and that just war theory at the jus ad bellum level of analysis would benefit by being extended to include the capabilities approach or something similar.

\section{The capabilities approach}

The capabilities approach originated in Amartya Sen's writings in the early 1970s and was developed by both Sen and Martha Nussbaum. Nussbaum's version of the capabilities approach differs from Sen's, although there are many substantive overlaps. ${ }^{22}$ The most important difference, as far as the purposes of this article are concerned, is that Nussbaum seeks to articulate capabilities as a basis for central constitutional principles that citizens have a right to demand from their governments. This right to demand appropriate constitutional principles stems from all citizens being viewed as morally equal, and that each individual deserves to be treated as an end. The central capabilities, she argues, together form a basic social minimum: a threshold level beneath which individuals live lives that are beneath human dignity, lives that are not worthy of being called fully human and even, 
perhaps, in some cases where the most important capabilities are compromised, lives that are not properly thought of as human at all. ${ }^{23}$

This, then, is the list of central capabilities as Nussbaum conceives of them in Women and Human Development: ${ }^{24}$

- Life. Not dying prematurely, or before one's life is so reduced as to be not worth living.

- Bodily health. Being able to have health and to be adequately nourished.

- Bodily integrity. Being able to move freely from place to place; having one's bodily boundaries treated as sovereign.

- Senses, imagination, thought. Being able to use the senses, to imagine, think and reason - and to do these things in a truly human way, informed and cultivated by adequate education. Being able to use one's mind in ways protected by freedom of expression. Being able to have pleasurable experiences and to avoid unnecessary pain.

- Emotions. Being able to have attachments to people and things outside ourselves. Not having one's emotional development blighted by overwhelming fear and anxiety or abuse and neglect.

- Practical reason. Being able to form a conception of the good and to engage in critical reflection about the planning of one's life.

- Affiliation. To be able to live with others, engage in various forms of social interaction and to show concern for other human beings. To be able to have the social bases of self-respect and non-humiliation.

- Other species. Being able to live with concern for and in relation to animals, plants and the world of nature.

- Play. Being able to laugh, play and enjoy recreational activities.

- Control over one's environment:

- Political. Being able to participate effectively in political choices that govern one's life.

- Material.Being able to hold property, and being able to seek employment.

- Personal.Being able to decide how and with whom you spend your time. ${ }^{25}$

Briefly, the capabilities approach as applied to human development is the view that human development is advanced by increasing people's capabilities to function, that is, what they are actually able to do and to be in a variety of areas of life. Before we 
apply these central capabilities to thinking about the justification of armed conflict, we need to consider how the list itself is to be understood.

The capabilities above should be understood as articulating a list of real freedoms: spheres of human life in terms of which human beings should have the substantive freedom to exercise choice. Nussbaum distinguishes between basic, internal and combined capabilities. Basic capabilities refer to capacities that individuals have, or their potentialities. These are necessary for the development of internal capabilities. Internal capabilities are capabilities which have developed in the right environment (under the right external conditions) and which are ready for functioning. ${ }^{26}$ Even when people have internal capabilities they may be prevented from functioning in accordance with them, hence combined capabilities. These are "internal capabilities combined with suitable external conditions for the exercise of the function". ${ }^{27}$ The list above is a list of combined capabilities, that is, capabilities that individuals actually have, as they are ready to function, coupled with the external conditions required to enable that functioning.

The social minimum that the list articulates can thus be clarified: as a basic social minimum, all citizens ought to have developed in such a way that they have these internal capabilities. Furthermore, the environment needs to be such that the external conditions required for this development and for the combined capabilities, are in place.

The capabilities in the list above are the central human capabilities, those necessary for human beings to meet the threshold of what it is to live a life worthy of human dignity, and thus to have a chance of living flourishing lives. Nussbaum has what might be called a two-tier view about what it is to live as human beings should live. The first tier might be called a 'minimally decent life', and the second 'a good life'. The capabilities are meant to help to specify what is meant by each of these. You need to have the all of the capabilities on the list for your life to be minimally decent. Moreover, you need to exercise those capabilities well (choose well) in order to live a good life.

Nussbaum argues that practical reason and affiliation play an 'architectonic' role with regard to the other capabilities. Practical reason and affiliation are more fundamental than the other capabilities in that:

- they are what infuse all capabilities with humanity, and as such are necessary conditions for their status as human capabilities; and 
- without them, the only level of functioning available to an individual is one that we would deem sub-human. ${ }^{28}$

The capabilities ${ }^{29}$ are not to be confused with actual functioning. The capabilities concern merely what we have the real freedom to be or to do; our functioning concerns what we actually choose to be or to do. The capabilities approach thus does not attempt to prescribe one way of functioning. As a development goal we should aim to promote capabilities, not actual functioning, in order to give citizens a choice. There are many ways an individual might choose to exercise a capability. Of those many ways, only some will result in flourishing, for flourishing requires that we make not merely choices, but good choices. But the account itself leaves open just what flourishing will consist of, that is, what counts as good choices, and it leaves open the possibility that there will be many ways to flourish. The capabilities, Nussbaum says, "may be concretely realised in a variety of different ways, in accordance with individual tastes, local circumstances and traditions". ${ }^{30}$

For the purposes of the next section, it may be useful to highlight here the key aspects of the capabilities approach as far as its application to armed conflict is concerned. These are:

- the architectonic role particularly of affiliation in relation to each of the other capabilities;

- the requirement that certain external conditions be in place if the combined capabilities are to be realised;

- the notion of a basic social minimum;

- the claim that as a basic social minimum these capabilities form the basis of constitutional principles all citizens have a right to demand from their governments; and

- the distinction between capabilities on the one hand and actual functioning on the other, which makes possible the multiple realisability of capabilities to function.

\section{From national defence to humanitarian intervention: Towards a capabilities approach to armed conflict}

The central question of our article remains - how might the capabilities approach, if incorporated into the just war framework, help to justify both national defence and humanitarian intervention? As already mentioned, this task is a subset of the goal of 
finding a revised version of just war theory that can address all the moral challenges of contemporary warfare, within a general framework of government responsibility.

As we saw earlier, in order to provide a plausible justification for the right to national defence we need to find "a value that is both objective and particular - it must be objective and recognizable as valid across cultures, yet still provide a reason for defending a particular state or community". "It is our contention that Nussbaum's capabilities approach provides just such a value.

\section{The capabilities approach as sufficiently particular}

The recognition of the importance of affiliation for human functioning and flourishing, together with the fact that the capabilities are explicitly understood to be multiply realisable, gives the approach the required embeddedness in particular communities and societies. The list, regarded as a basic social minimum, is not to be understood as prescribing particular ways of functioning, but rather as prescribing that citizens have real opportunities for choice. As such, the capability of affiliation -and affiliation as it will be expressed in each of the other capabilities as an architectonic value - will be realisable in a variety of ways. That is, particular communities will realise it in different ways.

It is clear then that our particular functioning, our particular choices to do and to be will be tied to our particular community, to our affiliation with these people. Thus, in a sense, my particular community is an essential prerequisite for my functioning and my possible flourishing. Arguably the most central notion in African philosophy is that of ubuntu, which, at its most fundamental level, is the notion that humans are essentially social beings. The classic statement of ubuntu is "a person is a person through other persons". ${ }^{32}$ The notion of ubuntu can accommodate this very profound insight about flourishing being tied to particular communities as well as other similar philosophical perspectives from around the world.

What is also clear is that, at least in the contemporary era, my community depends at least in part on the infrastructure provided by the state. As Charles Taylor put it in another context:

[T] he free individual or autonomous moral agent can only achieve and maintain his identity in a certain type of culture [which incorporates certain facets and activities]. But these and others of the same significance do not come into existence spontaneously each 
successive instant. They are carried on in institutions and associations which require stability and continuity and frequently also support from society as a whole - almost always the moral support of being commonly recognized as important, but frequently also considerable material support. These bearers of our culture include museums, symphony orchestras, universities, laboratories, political parties, law courts, representative assemblies, newspapers, publishing houses, television stations, and so on. And I have to mention also the mundane elements of infrastructure without which we could not carry out these higher activities: buildings, railroads, sewage plants, power grids, and so on. Thus [the] requirement of a living and varied culture is also the requirement of a complex and integrated society, which is willing and able to support all these institutions. ${ }^{33}$

Thus, if we take it for granted that the central purpose of the state should be to establish the necessary conditions for its citizens to have the central capabilities to function (at least up to a certain threshold), then it follows that the state has a duty and a consequent right to defend, with force if necessary, both the actual communities that fall within its jurisdiction and, indeed, its own existence.

\section{The capabilities approach as sufficiently universal}

As should be clear from the above, and as Nussbaum has defended it, the capabilities approach is universal: it seeks to secure the capabilities as a social minimum for all, given that each individual is an end. It seeks to provide the basis for constitutional principles that all citizens can demand from their governments. Nussbaum grounds this view in a plausibly universal and intuitively appealing account of the nature of a life worthy of human dignity. ${ }^{34}$ This account has, she points out, roots in many different traditions and is independent of any particular metaphysical or religious view. ${ }^{35}$

Rodin, it was pointed out above, argues that the right to national defence must be grounded in a value that is objective and recognisable across cultures. The capability of affiliation (and indeed the list taken as a whole) provides just such a value. Although I may not be able to appreciate the nature of a culture different to mine and its particular importance to you fully, I can appreciate that affiliation as it is expressed in culture is an integral, important part of human functioning and flourishing and, thus, that it is as important to you as it is to me. Used in this thin 
sense, affiliation (and indeed all the capabilities) is sufficiently general and thus recognisable across cultures.

\section{Justification and implementation}

The proposal above provides the basis for a prima facie presumption that all states have the right to national defence. Indeed, national self-defence and humanitarian intervention seem to suggest that states would only have the right to national defence if the basic social minimum were indeed in place. If the right to national defence is derived from the state's responsibility to ensure up to the requisite threshold, citizens' capabilities to function, then where that threshold is not secured does it follow that the right to national defence automatically falls away? Nussbaum's remarks on the political justification and political implementation of the capabilities approach, suggest that we should answer this question in the negative.

The capabilities approach as Nussbaum articulates it, is to be understood, she says, as the first step in an argument proceeding towards reflective equilibrium. ${ }^{36}$ In this regard she says:
... the intuitive conception of human functioning and capability demands continued reflection and testing against our intuitions, we should view any given version of the list as a proposal put forward in a Socratic fashion, to be tested against the most secure of our intuitions as we attempt to arrive at a type of equilibrium for political purposes. ${ }^{37}$

We follow this procedure, Nussbaum says, following Rawls, in a political domain with the aim of articulating a conception that people with differing conceptions of the good can agree to live by. As such, the procedure is ongoing and, in order to achieve completion, it would need to consider not only all the judgements of fellow citizens but also competing theoretical conceptions, it is likely to remain forever incomplete. ${ }^{38}$ This means that practical implementation of the approach should be cautious. It also means that in all implementation space has to be left for the nation state to play a fundamental role. We can recommend the approach as a good idea to politicians who want to use it as the basis for policy; we can also go further: in the case of a community of nations having adopted the approach, it can be "commended strongly to other nations" according to Nussbaum. Moreover, the aim should be that the international community reach agreement on the capabilities list, as a set of commitments that individual nations have to their citizens and as a set of goals to 
realise through cooperative international action. However, given the architectonic role of practical reason as a capability of each citizen and the importance of the political liberties in the account, practical implementation, says Nussbaum, must remain to a large extent the job of citizens in each nation. ${ }^{39}$

These remarks suggest that it would be too hasty to claim that the prima facie right of the nation state to national defence is conditional on the nation state having actually realised the capabilities as a basic social minimum for each citizen. Given that it is a prima facie right, however, can we say anything more definite about cases when this right certainly would fall away?

\section{Humanitarian intervention and the doctrine of proportionality}

It is the authors' contention that this prima facie presumption of the right to national defence does leave the door open to humanitarian interventions when the state in question is guilty of serious violations of human dignity. In such a case the offending government has effectively given up its right to defend itself by undermining the fundamental intuition which underpins the capabilities approach. The right to national defence is derived from the responsibility of government to provide the conditions that would enable citizens to live lives at least minimally worthy of human dignity. Although we may not, and may never, reach certainty on the precise list of capabilities that express this idea of the social minimum, it does seem that the international community can agree on cases where the basic intuition underlying the approach is violated. As a consequence, the offending state cannot claim that a humanitarian intervention, in such a case, is a violation of its sovereignty, and it cannot claim the right to national defence. The state or coalition of states that intervenes under these circumstances is therefore guilty of no wrong, as long as the intervention itself is a measured response to the harm in question. The doctrine of proportionality must, here, play a key role in our determination of when, if ever, such interventions would be justifiable. ${ }^{40}$

\section{Conclusion}

Our suggestion, then, is as follows: If incorporated as part of the just war framework, the capability approach is both sufficiently universal and sufficiently particular to ground the right to national defence, that is, it gives us a moral reason not simply to defend order, but to defend a particular form of order - our order. However, on this account the right to national defence does turn out to be conditional. This, as we mentioned above, was the downfall of Waltzer's "self- 
determination" approach, according to Rodin. However, it seems the capabilities approach is superior here first, and primarily because of the explicit architectonic role played by affiliation, and secondly, because of the explicit use of the notion of a threshold level, or basic social minimum. The first feature makes the capabilities approach more explicitly sensitive to the importance of particularities of culture and thus the common life, whilst still remaining universal. The second gives the capabilities approach better resources for distinguishing when it is the case that the prima facie right to national defence falls away.

Together with Nussbaum's caution that "[C]apabilities theory would be a prescription for tyranny if it bypassed the nation" ${ }^{, 41}$ we should be careful to note the importance of the doctrine of proportionality here. Given the ongoing nature of the political justification of the approach, the central importance of individual autonomy and political liberties, and high costs of armed conflict for human development and human flourishing, the prima facie right to self-defence falls away for a particular country only in the case where humanitarian intervention is justified. The aforementioned justification stems from extreme cases that "shock the conscience of mankind" where a population is suffering serious harm as a result of internal war, insurgency, repression or state failure, and the state in question is unwilling or unable to halt or avert the suffering, such that the principle of non-intervention yields to the international responsibility to protect.

Much, of course, remains to be explored if this suggestion of incorporating the capability approach into just war theory is to become a reality. Our goal in this article has been to give some preliminary reasons for thinking that such an investigation could well yield valuable results. We hope that it will stimulate further debate on this topic.

\section{End notes}

${ }^{1}$ It seems that George Santayana should receive the credit here. See the discussion at http://plato-dialogues.org/faq/faq008.htm.

${ }^{2}$ Martin L. Cook, The Moral Warrior: Ethics and Service in the U.S. Military, Albany, NY: State University of New York Press, 2004, p. 112.

${ }^{3}$ George R. Lucas, Jr., 'From jus ad bellum to jus ad pacem: re-thinking just-war criteria for the use of military force for humanitarian ends' in, Deen K. Chatterjee and Don E. Scheid (eds.), Ethics and Foreign Intervention, Cambridge: Cambridge University Press, 2003, pp. 72-96.

${ }^{4}$ An interesting recent response to this challenge is the project that has been launched by the Global Ethics and Religion Forum, 'Revisiting Just War Theory for 
the $21^{\text {st }}$ Century', which aims to amend just war theory to be inclusive of all of the world's major religious and cultural worldviews.

5 See particularly Brian Orend, 'Justice after War', Ethics \& International Affairs, 16 (1), Spring, 2002, pp. 43-56.

${ }^{6}$ See for example Jus ad Pacem by Michael S. Pendergast III, http://www.uwsp.du/history/WIPCS/JSPC2004/Pendergast.pdf (accessed 1 October 2007).

${ }^{7}$ Martha Nussbaum, Women and Human Development: The Capabilities Approach, Cambridge: Cambridge University Press, 2000, p. 12.

${ }^{8}$ See Deane-Peter Baker, 'Defending the Common Life: National Defence after Rodin', Journal of Applied Philosophy, 2006, 23 (3), pp. 259-275.

${ }^{9}$ Some of the material in this section draws on Deane-Peter Baker, 'Defending the Common Life: National Defence after Rodin', Journal of Applied Philosophy, 23(3), 2003, pp. 259-275.

${ }^{10}$ David Rodin, War and Self-Defense, Oxford: Clarendon Press, 2002, p. 129.

${ }^{11}$ Rodin, 2002, p. 140.

12 Ibid.

${ }^{13}$ Rodin rejects one other interpretation out of hand, that which comes to light in one reading of the work of Hegel, namely the view that 'the common life is a source of value independent of its value for individual persons' (Rodin 2002, p. 143). Rodin rejects this view on the grounds that moral explanations (of which the pursued justification of national-defence is one) must derive their legitimacy from their contribution to individual human life.

${ }^{14}$ Rodin, 2002, p. 149.

${ }^{15}$ Rodin, 2002, p. 155.

${ }^{16}$ Rodin, 2002, p. 152.

17 International Commission on Intervention and State Sovereignty, The Responsibility to Protect, Ottawa: International Development Research Centre, 2001, p. XI. See UN Secretary General, Kofi Annan's report to the United Nations General Assembly of March 2005, entitled 'In larger freedom: towards development, security and human rights for all', where he endorsed the Commission's findings.

${ }^{18}$ Mervyn Frost's discussion of this issue in his Ethics in International Relations: A Constitutive Theory, Cambridge University Press, 1996, pp. 199-201 is a wellargued example of this view.

19 Though, as we have seen, Rodin argues that even in this apparently clear-cut case, just war theory fails to deliver.

${ }^{20}$ See Terry Nardin, The Moral Basis of Humanitarian Intervention, The Center for Global Peace and Conflict Studies, University of California, Irvine, Working Papers 2000,http://www.cgpacs.uci.edu/research/working_papers/terry_nardin_humanitaria n_intervention.pdf (accessed 14 December 2007).

${ }^{21}$ Mona Fixdal and Dan Smith, "Humanitarian Intervention and Just War", Mershon International Studies Review, 1998, 42, p. 298. 
${ }^{22}$ Nussbaum spells out the distinctions and overlaps here in Nussbaum, 2000, pp. 11-15.

${ }^{23}$ Nussbaum's uses the terms 'human being' and more particularly 'a human life' as ethical terms, that is, as evaluative concepts. However, she suggests, especially in some of her earlier writings where she articulates the Aristotelian grounding of the capabilities approach, that the descriptive (or scientific) terms 'human being' or 'human life' are just evaluative concepts. See "Aristotle on Human Nature and the Foundations of Ethics" in J. E. T. Altham and R. Harrison (eds.), World, Mind, Ethics. Cambridge: Cambridge University Press, 1995. For the purposes of this article, we accept her use of 'human being' and 'a human life' as evaluative concepts without thereby taking a stand on whether the evaluative judgement of whether someone is living a life worthy of being called human itself settles the descriptive question of whether a life is human or not. It is not the case that the further, descriptive, claim is required for justification for the capabilities approach, as Nussbaum herself seems to recognise in Women and Human Development.

${ }^{24}$ Nussbaum, 2000, pp. 78-80.

${ }^{25}$ This aspect of capability 10 appears in the version of the list in Nussbaum, 1999, p. 42.

${ }^{26}$ This use of the term 'functioning' is clarified below.

${ }^{27}$ Nussbaum, 2000, p. 84.

${ }^{28}$ See especially Nussbaum, 2000, p. 129.

${ }^{29}$ From here on when we talk of the capabilities we mean the combined capabilities on the list.

${ }^{30}$ Nussbaum 2000, p. 105.

${ }^{31}$ Rodin 2002, p. 155.

${ }^{32}$ Nono Makhudu, "Cultivating a climate of co-operation through ubuntu", Enterprise, August, 1993, 68, pp. 40-41.

${ }^{33}$ Charles Taylor, 'Atomism' in Philosophy and the Human Sciences: Philosophical Papers, 2, Cambridge: Cambridge University Press, 1985, pp. 205-206.

${ }^{34}$ Nussbaum defends the universality of the capabilities approach, and indeed the need for a universal account, in a number of her writings. See especially Nussbaum, 2000, Chapter one. Of course, our account rests on the presumption that this defence is successful. Although we think that it is, there is not space to address this issue properly here.

${ }^{35}$ Nussbaum, 2000, p. 101

${ }^{36}$ Nussbaum, 2000, p. 101. Nussbaum spells out this Rawlsian notion in detail here.

${ }^{37}$ Nussbaum, 2000, p. 77.

${ }^{38}$ Nussbaum, 2000, p. 102-103.

${ }^{39}$ Nussbaum, 2000, p. 104.

${ }^{40}$ Although Nussbaum says that in such cases it would seem appropriate for nations to use economic and other pressures, particularly in cases where the offending state in question is non-democratic, she stops short of recommending humanitarian intervention. See Nussbaum, 2000, p. 104.

${ }^{41}$ Nussbaum 2000, p. 104. 